\title{
PARA PENSAR LA CRÍTICA DE POESÍA EN AMÉRICA LATINA
}

\author{
POR \\ Josu LANDA \\ Facultad de Filosofia y Letras \\ UNAM
}

\begin{abstract}
Cuando me represento la imagen de un lector perfecto, siempre resulta un monstruo de valor y curiosidad, $\mathrm{y}$, además, una cosa dúctil, astuta, cauta, un aventurero y un descubridor nato. En fin: mejor que lo he dicho en Zaratustra no sabría yo decir para quién únicamente hablo en el fondo; $i$ a quién únicamente quiere contar él su enigma? "A vosotros, los audaces buscadores $\mathrm{e}$ indagadores y a quienquiera que alguna vez se haya lanzado con astutas velas a mares terribles; - a vosotros, los ebrios de enigmas, que gozáis con la luz del crepúsculo, cuyas almas son atraídas con flautas a todos los abismos laberínticos; - pues no queréis, con mano cobarde, seguir a tientas un hilo y que, allí donde podéis adivinar, odiáis el deducir ..."
\end{abstract}

F. Nietzsche

1. No es tarea de un filósofo aislado emprender un balance de la crítica de poesía algo diferente, en rigor, a una "crítica poética" - conocida en América Latina, durante los años 70. Tal clase de empresa sólo puede ser obra de una amplia conjunción de mentes diversas. En todo caso, una vez metidas sus narices en el vasto mundo de la crítica de poesía, lo que el filósofo puede y debe hacer es pensar su sentido, conforme a las exigencias de una teoría de la poesía. Las líneas subsiguientes pretenden sugerir algunas posibilidades con miras a una iniciativa teórica de ese tipo, teniendo en mente algunos casos paradigmáticos de ejercicio de la crítica de poesía en América Latina en el periodo señalado. Eso ya habla de unos límites explícitos. A ellos hay que agregar los que son propios de un texto destinado a ser publicado en una revista, como éste.

2. Se puede entrar en materia, consignando la imposibilidad de una periodización decenal de las escuelas y modos hegemónicos de crítica de poesía en Latinoamérica. Ciertamente, una década constituye ya una referencia temporal y, en tanto que tal, puede ser vista como el marco de un cierto tipo de ejercicio más o menos modélico de la crítica de poesía. Pero una aproximación directa a determinadas obras fraguadas, en la década de los 70, por autores como Octavio Paz, Guillermo Sucre, Julio Ortega, Roberto Fernández 
Retamar, José Emilio Pacheco, Juan Liscano, Saúl Yurkiévich, Blas Matamoro, Tomás Segovia y algunos más que se han aplicado a fondo en un examen crítico de la poesía, permite constatar en seguida una diversidad de procederes, actitudes, tesis. Dicha diversidad habla de opciones críticas que se vienen ejerciendo desde antes incluso de los años sesenta, no para quedarse cómodamente afincados en alguna eventual certidumbre inexpugnable, sino para anunciar modelos críticos que habrán de madurar durante los años 80. Tal vez, lo más que podrá afirmarse con un mínimo de seguridad es que durante buena parte de los 70, los principales críticos de la poesía en América Latina procesan creativamente las ideas de la llamada "nueva crítica". Desde luego, tampoco en ese período desaparecen del todo los modelos críticos anteriores, sustentados en supuestos como el de la función social y política de la obra poética o en los ideales de las ya un tanto anacrónicas vanguardias. También hay que tener presente, en ese tiempo, la fuerza de cierto cientificismo -corriente enfrentada a todo lo que suene a "crítica impresionista" y artesanalfanáticamente asumido, sobre todo en los medios académicos. Sin embargo, la mejor crítica de poesía del momento demuestra haber buceado en las teorías críticas de Barthes, Blanchot, Mounin, Jakobson y la más vasta gama de autores estructuralistas y formalistas, cuyo influjo amenaza con ser universal e irresistible a partir de la década de los años 60 , pero lo hace sin ahogarse en ellas, es decir, sin dejar de generar tesis críticas propias. De hecho, la crítica de poesía latinoamericana más significativa adopta buena parte de los referentes de la reflexión crítica de pretensiones científicas y filosóficas, pero sin perder su autonomía de pensamiento ni renunciar a una escritura de elevado gusto. En realidad, ha sido el ensayo -en su condición de género situado a mitad de camino entre el tratado riguroso y la relación estéticamente valiosa de los movimientos de la subjetividad y las impresiones que su apercepción suscita - la opción expresiva que se ha impuesto abrumadoramente en la crítica de poesía más influyente en América Latina.

Así pues, más que un límite rígido, un decenio debe ser visto como un referente útil desde la perspectiva estrictamente temporal. Ahora bien, desde el punto de vista teórico es más indicado examinar expresiones concretas de ejercicios críticos más o menos modélicos, de algún modo "representativos" (aunque ello suponga algunos problemas de consideración), con una independencia razonable respecto de las determinaciones temporales. Tómese, como ejemplo, el caso de Octavio Paz. Este es un autor de influencia decisiva en todo el ámbito de la crítica de poesía latinoamericana y de habla hispana, tanto en la década de los 70 como en la anterior y en la posterior. De hecho, algunas de sus obras logran causar su impacto más fuerte en el decenio de los 70 - e incluso en la de los 80 - pese a que aparecen por primera vez mucho antes. Por otro lado, no se puede desvincular el trabajo crítico realizado por Paz durante la década de los setenta del que despliega en las anteriores. Ello significaría negar una evidente continuidad en toda la producción crítica del autor mencionado. Obras como El signo yel garabato (1973), Los hijos del limo (1975), El mono gramático (1974), In/mediaciones (1979) constituyen la proyección de El arco y la lira (1956), Cuadrivio (1965), Los signos en rotación (1965), Puertas al campo (1966), Corriente alterna (1967), Conjunciones y disyunciones (1969) ... y conforman a su manera una totalidad, aunque no propiamente un sistema crítico. En consecuencia, es teóricamente más provechoso considerar las bases en que se sustentan las expresiones de la crítica de poesía realizada por Paz en la década de los setenta, dado que tienen un carácter 
paradigmático. Lo mismo se puede decir, por supuesto, respecto de la obra crítica de otros autores relevantes.

3. Como ya se ha señalado en el punto anterior, una de las evidencias con que se presenta la crítica de poesía en América Latina, durante el período que aquí interesa es su conexión con la amplia familia de autores, escuelas y procederes reducible a la expresión "nueva crítica". Conforme al método que se acaba de sugerir, ello significa que los críticos que aquí interesan más, por su relevancia han protagonizado una aventura teórica marcada por la conjunción de las tendencias más actuales y de pretensión más universal (procedentes de una triple "metrópoli": Francia, Inglaterra y E.E.U.U.) con una voluntad de estilo, de creación literaria, en buena medida ajena a los modi operandorum propios de la academia. En las últimas décadas, América Latina ha conocido un proceso gradual de academización de la crítica, pero no parece descabellado aducir, es decir, formular la hipótesis de que ello no se ha traducido en un predominio de los procederes académicos en la reflexión más significativa sobre la poesía. Ciertamente, en América Latina cada vez puede resultar más difícil una disociación entre el crítico y la academia. Hoy día, también en nuestro orbe cultural, la mayoría de los críticos está empeñada en hacer carrera como profesores e investigadores de literatura. Sin embargo, también se aprecia que el crítico latinoamericano contemporáneo se aprovecha de todo lo académico hasta donde le conviene, al tiempo que elige opciones epistemológicas y formales bastante reñidas con las que consagra el mundo universitario. Para decirlo con palabras caras a Huizinga, ha habido siempre una vocación de seriedad en la mejor crítica de poesía latinoamericana; lo que le ha llevado a echar mano de la filosofía y cierta ciencia, a sabiendas de que, como advierte Barthes, "La critique n'est pas la science" (Critique et verité 63). Esto no niega que exista, en América Latina, un cultivo de la crítica académica cuantitativa y cualitativamente importante. Por otra parte, tampoco significa que estamos ante una crítica superior y otra inferior (más academicista). Simplemente, se trata de niveles y modelos críticos diferentes pero interconectados. Se trata, en suma, de vertientes del trabajo crítico dotados de una especificidad, que obliga a impulsar procesos de estudio y comprensión igualmente específicos. Vale decir, la crítica de vocación academicista exige un balance distinto, a la par de que se requiere de un examen especial de sus complejos nexos con lo que podría caracterizarse como una "crítica poética de la poesía".

Es esta última modalidad de la crítica de poesía la que interesa abordar aquí, teniendo en mente - como ya se ha sugerido en el punto 2- algunos de sus exponentes más destacados. Al respecto, conviene empezar a considerar: a) sus conexiones con diversas disciplinas y, muy especialmente, con la filosofia; b) su basamento filosófico.

4. La voluntad de estilo - por ende, la literariedad- del ensayo crítico, en América Latina, no ha sido óbice para la genuina racionalidad de que también ha estado dotado. La crítica de poesía ejercida en América Latina no parece admitir las imputaciones que hace Paul de Man a ciertos movimientos y sectores críticos, en el sentido de "resistirse a la teoría". La exigencia de una escritura de valía estética no ha estado reñida con la reivindicación de un rigor teórico que ha tratado de hallar su fundamento en la mayoría de las ciencias del hombre(historia, sociología, etnografía, arqueología, historia de las religiones, politología, 
psicología, psiquiatría ...), las ciencias del lenguaje (semiótica, semiología, lingüística, fonología ... también podría incluirse aquí algo de la filosofía contemporánea del lenguaje) y las disciplinas más directamente relacionadas con la poesía (retórica, poética, estética, etc.). De ese modo, la crítica de poesía de nuestro tiempo - y concretamente la que se realiza en los años 70- aparece a primera vista como la convergencia de una pluralidad de disciplinas.

¿Cuál es el sentido de dicha convergencia? Se debe dar una respuesta múltiple a esta pregunta. En primer lugar, la crítica de poesía conjuga praxis con póiesis. Así, la crítica de poesía aparece como una articulación de dispositivos, técnicas, saberes y procederes (así como una gran gama de factores de contexto, como los "valores poéticos", por ejemplo) cuyo centro lo conforman la intuición y el juicio crítico. "Intuición" significa aquí descubrimiento y contemplación de eventos, a partir de una relación entre sujeto crítico y objeto poético. Alrededor de dicha intuición operan diversas creatividades (es decir, potencialidades poiéticas; $v . g$., una poiesis hermenéutica y una poiesis escritural capaces de dar cuenta de un epistema crítico e introducirlo en la dinámica de una comunidad poética). Todo parece indicar que el recurso de la crítica de poesía a las disciplinas referidas halla su razón de ser en que así puede inducir una determinada intuición crítica, a la vez que puede ayudar a fundamentar una obra crítica. No parece haber, pues, un profundo nexo entre la crítica de poesía (cuya esencia, en el plano epistemológico y estético es la intuición del acontecer poético) y las disciplinas en referencia. La relación entre ambas parece determinada por motivaciones ajenas a la crítica de poesía en sí, como la evolución de la poesía y de la crítica de poesía misma, y no por razones intrínsecas al trabajo crítico. En suma, dichas disciplinas o ciencias parecen ser simples auxiliares de la intuición y el juicio críticos; plataformas de cierta clase de argumentación, que no puede renunciar a su profunda raíz intuitiva.

Si lo antedicho es verdad, resulta lícito cuestionar la supuesta superioridad de la crítica de poesía científica - por llamarla de alguna manera - frente a la llamada "crítica impresionista". Si razonablemente se equipara "impresionista" con "intuitiva", se entenderá que la crítica de poesía académica da cuenta de opciones de argumentación crítica determinadas por referentes exegéticos asociados a diversos saberes. Pero el núcleo de dicha crítica académica seguirá siendo siempre, incluso a su pesar, un proceso intuitivo.

5. Lo que se acaba de señalar se aplica al caso de los vínculos entre filosofía y crítica de poesía. Hasta donde se puede apreciar, al menos en América Latina, la filosofia ha sido vista por la crítica de poesía de las dos últimas décadas como un factor de erudición más, dentro de la obra crítica. A partir de un arraigado sentido de especificidad, la crítica de poesía ha echado mano de los filosofemas que le han permitido generar cierta ensayística enjundiosa. Cuando resulta razonablemente posible aducir cierto existencialismo en la poesía de Alí Chumacero, por ejemplo, no faltarán los críticos que traten de argumentar en el sentido de dicha corriente filosófica. En otros casos, puede justificarse el amparo de la fenomenología o el de alguna filosofía del lenguaje o hermeneuticista o el del freudismo, el marxismo o cualquier otra expresión de las grandes teorías, sobre todo, del s. XX. A esta actitud han contribuido, seguramente, las incursiones de filósofos como Kierkegaard, Heidegger, Sartre, Derrida, Deleuze, etc. en los dominios de la reflexión sobre poesía. 
También ha influido la exégesis crítica de autores como Blanchot, Bataille, por ejemplo, en un acercamiento a lo poético teñido de filosofia.

Contra toda apariencia, este modo de relación entre crítica de poesía y filosofía sin duda, dominante - pone de bulto el abismo que separa a ambas. Ya Paul de Man había destacado que "la teoría literaria bien puede haberse vuelto un objeto de interés legítimo de la filosofía, pero no puede ser asimilada a ella ..." (La resistencia a la teoría 18). En efecto, la crítica de poesía se ocupa en aquello que de inteligible y relativamente comunicable podría intuirse en un objeto no sólo particular, sino minado por la "diferencia" ontológica. La filosofía, por su parte, no puede renunciar a su misión de descubrir lo universal en esa misma clase de objetos, so pena de desnaturalizarse, de dejar de ser verdadera filosofía. De ahí que la presencia del filosofema en la obra crítica sólo se dé como una yuxtaposición artificiosa. De ahí también lo absurdo de las pretensiones cientificistas de la crítica académica. La naturaleza misma del objeto crítico y el tipo de procesos en que se sustenta la crítica de poesía hacen imposible la constitución de ésta en una ciencia stricto sensu. Hace bien la crítica de poesía en tratar de limitar o atemperar los virtuales excesos de la subjetividad crítica y sus pasiones, recurriendo a la ciencia y la filosofía. También merecen aplauso sus intentos de reducir todo viso de arbitrariedad en la doxa crítica, por medio de referencias de cariz científico. Pero no se debe olvidar la vieja verdad de que no hay ciencia de lo particular. La crítica de poesía está condenada a ser no-científica, a no rebasar los límites de la doxa, por mucho que ésta se revista de erudición más o menos seria; su papel en el horizonte de la cultura es distinto a los de la filosofía y la ciencia. La crítica de poesía latinoamericana de nuestro tiempo, obligada por razones históricas y culturales a tomar como referente primordial a la "nueva crítica", no parece haber tenido conciencia de este hecho.

6. Con aceptable seguridad, esa disyunción entre filosofia y crítica de poesía tiene que ver con una ontología del poema. Mientras la crítica de poesía - pese a las libertades formales de que goza y a la laxitud de sus compromisos epistemológicos-sólo puede partir de la certeza de un objeto poético existente y dado, la filosofia empieza por inquirir sobre la naturaleza de la cosa llamada "poema" y pone en cuestión todo lo que para la crítica de poesía es certidumbre.

La crítica de poesía de los años 70 y buena parte de los 80 , en América Latina, no puede funcionar sin el reconocimiento de una obra poética en términos de un datum, de una substancia dada y autorreferencial. Hay, pues, crítica de poesía en la medida en que se acepta la premisa de un sólido fundamento ontológico: la obra poética. Ciertamente, dicho modelo de crítica de poesía no ha superado el espejismo del objeto poético, en último término firme. No lo ha logrado incluso a pesar de su apertura a las audacias de las vanguardias poéticas y de la nueva crítica. De hecho, la crítica de poesía en referencia no parece capaz de dar un salto de esa clase, debido a que ello supondría una revolución en el lenguaje crítico, que se vincularía más con los procederes de filosofias radicales, "post-metafísicas" (como cierto nietzscheanismo, algunas obras de Heidegger, la llamada "filosofia de la diferencia", la corriente del "pensamiento débil" y pocas más) que con los de la propia crítica de poesía. En realidad, sólo algunas de las corrientes críticas actuales demuestran tener conciencia de este hecho. Los ramalazos quizá tardíos de algunas tesis derrideanas y de Bajtin, incluso 
del Wittgenstein de las Investigaciones filosóficas, por ejemplo, dan cuenta de ello. Pero no se puede dejar de insistir en que se trata de un acceso superficial a una ontología del lenguaje y del poema realmente radicales.

7. Aceptar el supuesto de una substancia poética —ese "oscuro objeto del deseo crítico" llamado "obra"- susceptible de ser sometida a crítica, comporta a su vez: reivindicar una conexión indisoluble y compleja entre lectura e intuición; y reconocer una escisión entre escritura y lectura poéticas y, por tanto, entre poeta y lector.

La intuición crítica pasa por un proceso de compenetración del sujeto crítico con una materia verbal que se asume como cierta unidad de sentido más o menos evidente. Dicha compenetración puede ser referida con el vago vocablo de "lectura". De ese modo, la crítica de poesía aparece como un vasto y dinámico sistema de lecturas, tanto más complejo cuanto que debe afrontar el hecho de la pluralidad de interpretaciones que puede suscitar toda creación verbal; la realidad inquietante del residuo de indeterminación que su misma naturaleza trópica impone a todo lenguaje poético. Un sistema, en fin, cuya razón de ser es constituir un metalenguaje a partir del lenguaje presente en el objeto poético.

Esto habla de una lectura consciente de sí. Toda lectura puede ser un proceso intencional; pero la procura de una intuición-judicación crítica implica una lectura cuya intencionalidad está ya predeterminada por el leer mismo. No es posible una crítica de poesía que no se sustente en un "leer para", definido con antelación. Desde luego, ésta no es una peculiaridad de la lectura crítica, pero sí establece claramente su desvinculación, en último término, con lecturas realmente ociosas (es decir, de intencionalidad no controlada). De modo, pues, que la crítica de poesía sólo puede darse sobre la base de una mediación finalista y, en el fondo, instrumental entre el sujeto crítico y su objeto. Esto es, el "para" de los procesos críticos apunta inevitablemente no sólo a la intuición, sino también al juicio. De hecho, la crítica de poesía se da como un "intuir lo poético para un juicio crítico".

Ahora bien, hay diferencias obvias entre el simple juicio de gusto y la valoración crítica de objetos con intencionalidad poética. Aquél es mucho más amplio y general (como se sabe a partir de las reflexiones de Platón, Aristóteles, Pseudo-Longino, Burke, Kant, Hegel, Nietzsche, Kierkegaard y otros, acerca de lo bello y lo sublime)y, sobre todo, es espontáneo y desinteresado. Por su parte, el juicio crítico supone una red de mediaciones, procesos, intereses, relaciones. Pero cabe preguntarse si dicha conjunción de elementos anula un proceso esencialmente judicativo. Todo parece sugerir que no; que no hay crítica de poesía, sin una activación de eso que Kant entendía -no importa cuán problemáticamente-como "facultad de juzgar". Así pues, los soportes y mediaciones del ejercicio judicativo crítico implican una diferencia de grado, frente al juicio estético "puro". Dicho de otro modo, en su raíz, la crítica de poesía es juicio estético. No parece haber una distinción esencial entre juicio crítico y juicio estético. Lo cual refuerza la idea de que, cuando la crítica de poesía recurre a referentes de juicio procedentes de las ciencias, la filosofía, etc., sólo amplía y enriquece las mediaciones que separan a un juicio crítico de sus bases directamente estéticas. Parece claro que la crítica de poesía de los años 70, en América Latina, en la medida de su dependencia con respecto a la "nueva crítica", no tenía conciencia de este problema y empleó demasiada energía en distanciarse de una "crítica impresionista", es decir, basada en juicios estéticos, en el sentido clásico del término (esto es, "naturales"). 
La suposición de una diferencia de fondo entre juicio estético y juicio crítico parece haber potenciado una tendencia a convertir los medios del juicio crítico en un fin en sí. Se debe entender que el juego de la crítica de poesía consiste precisamente en acceder al acontecimiento poético, con base en una intuición que, al mismo tiempo, abra cauces a la judicación crítica. Es legítimo — conforme a las "reglas" de dicho "juego"— recurrir al máximo posible de soportes de tales intuición y judicación. Esto es, tiene pleno sentido una crítica de poesía sustentada en referentes hermenéuticos y críticos procedentes de los saberes del caso. Lo que no parece calzar con la naturaleza a la vez intuitiva y judicativa de la crítica de poesía es la propensión a convertir la procura de tales referentes en el supuesto fin último de la crítica de poesía. Parece pertinente, en consecuencia, buena parte de las objeciones de Steiner a la crítica de nuestro tiempo.

Por otro lado, también desde la perspectiva de la filosofía, es decir, de un pensamiento de la crítica de poesía, resulta evidente el carácter creativo de ésta. Más allá de los alegatos marcadamente dóxicos de antiguos defensores de la crítica, como v.g. Oscar Wilde, el reconocimiento del fondo intuitivo-judicativo de la crítica de poesía exige aceptar sin más su creatividad. No en vano se afanó Kant en demostrar con marcado provecho la índole creativa de todo proceso estético y judicativo, desde sus niveles más elementales. El culto a las prácticas y valores academicistas, del que no ha estado exenta nuesta crítica de poesía en un pasado relativamente reciente, sólo ha podido darse en la medida en que se ha ignorado de mil modos esa raigal creatividad del trabajo crítico.

8. El problema que quedó sin tratar en el punto anterior es el de las escisiones escrituralectura/poeta-lector. Es, sin duda, uno de los problemas más difíciles de toda filosofía de lo poético. Antes, durante y después de los años 70, la crítica de poesía sólo ha podido funcionar sobre la base del supuesto tácitò o explícito de tal escisión. Ciertamente, la crítica de poesía no ha ignorado las dificultades que comporta este asunto. Desde las más tempranas vanguardias poéticas y artísticas contemporáneas, se ha visto la conveniencia de matizar -cuando menos-ese corte tan brutal entre los términos de una relación inevitable, como la que se da entre creadores y lo que, con exceso de simplismo, se designa como "receptores" de poesía o de arte. Las vanguardias han aportado a la crítica de poesía la idea válida de una creatividad situada en el topos extratextual en que acontece lo poético (no, desde luego, en una inexistente "recepción"). "Si la Forma ha muerto, todo está permitido", parece haber sido la divisa de las vanguardias. Ello habla de una actitud con repercusiones importantes en la crítica de poesía, pero sin que haya podido afectar sus más profundas raíces ontológicas. Desde la constatación lúcida de esta clase de realidades, la crítica de poesía ha venido asimilándose progresivamente a una aventura cercana al salto en el vacío. Sin embargo, sólo a partir de una crítica radical a la metafísica occidental tradicional ha aflorado una ambición más consistente de "desconstrucción" de la dicotomía planteada. Que todo ello haya quedado en ambición insatisfecha es harina de otro costal. La debilidad de una crítica de poesía impotente ante tal clase de metafísica binaria parece estar en la raíz de los problemas que aquejan a la actividad poética, en la era de la industria cultural: distanciamiento progresivo entre los movimientos poéticos vivos y una crítica hiperespecializada, disolución de los paradigmas clásicos de lo poético (y consabida anomia y esquizofrenia críticas), y otros problemas de los que dará cuenta mucho mejor una sociología de lo poético. 
En realidad, se trata de una dificultad que rebasa las lindes de la crítica de poesía. Su verdadero ámbito es la ontología de lo poético. Mientras la crítica de poesía no supere su actitud parasitaria ante la filosofía no tendrá más remedio que seguir sufriendo las consecuencias de su déficit metafísico. En concreto, esto significa que la crítica de poesía siempre termina sucumbiendo a un "esencialismo poético"; es decir, siempre pierde de vista la naturaleza radicalmente relacional de todo lo poético. La crítica de poesía se ha convertido en un juego de lenguaje que no ha podido integrar el hecho de que no hay referentes absolutos de lo poético (no hay poemas en sí, poemas "realizados" de una vez y para siempre; se requiere de criterios de decisión de lo poético, así como de procesos y espacios de realización de lo poético), de que lo poético rebasa toda actividad textual, de que no es posible una escritura y una lectura puras y de que, por ende, la figura clásica del poeta es una ilusión sustentada más en patrones éticos que en realidades antropológicas esenciales y definitivas.

Las implicaciones de lo que se acaba de señalar afectan a la filosofía misma. Se evidencian más que nunca las insuficiencias de una filosofia de lo poético, que se conforma con confeccionar poéticas o se ocupa en psicologías absurdas o en especulaciones éticas, en torno a lo poético, o en una hermenéutica $a d$ hoc de textos poéticos asumidos como tratados metafísicos. Si el poema no es el objeto sólido que hemos creído y, por tanto, no es dable una confrontación sujeto-objeto, en punto a los procesos poéticos (incluidos los de naturaleza crítica); si no es posible escindir taxativamente los procesos de producción textual y los de realización poética, será necesario plantearse una ontología de lo poético en términos de una topología. Esto es, en términos de actividades creativas, dialógicas, hermenéuticas, críticas ... que pongan a prueba la producción textual con vocación poética (no poemas a priori), así como de descripciones teóricas provisionales y transreferenciales de tales actividades, del movimiento poético que suscitan, en el seno de comunidades poéticas y de los procesos en que descansa la realización peculiar de lo poético. En definitiva, una topología entendida como identificación de las condiciones de realización dinámica de la producción poética, en una comunidad de referencia.

Desde luego, un nuevo pensamiento de lo poético y de la crítica de poesía también debería considerar las dimensiones éticas que también le son propias. La radical relacionalidad de toda realidad poética pone de relieve una intersubjetividad, una interacción intencional de personas. Eso que Starobinsky ha llamado el "don al otro", esa deferencia de reconocer alteridades plurales, forma parte de toda topología del poema y también del trabajo crítico. Sin embargo, todo abordaje de lo poético y de la crítica de poesía, desde una perspectiva estrictamente práctica, debe sustentarse en una plataforma ontológica. De ahí que su consideración deba esperar a una afirmación teórica de la dinámica topológica de lo poético.

9. El modelo crítico tradicional comporta, como se ha visto, una dependencia recíproca entre hermenéutica, intuición y juicio. A fin de cuentas, la crítica de poesía resulta en bendecir o maldecir, aceptar o rechazar, consagrar o execrar un objeto cuya solidez ontológica y su condición de obra poética no se cuestiona. Puede decirse que ése ha sido el sentido de la crítica de poesía. Esta ha tenido que pagar un precio peculiar, por conformarse con tal clase de fundamentación metafísica. Un precio consistente en convertirse en factor de poder. La gradual academización de la crítica de poesía, así como 
su apego a los paradigmas epistemológicos entronizados por la cosmovisión moderna occidental han encontrado su razón de ser en procesos judicativos basados en admisiones o exclusiones, más o menos sumarias, de entidades asumidas de antemano como objetos de juicio. A partir de esta realidad, no debe asombrar la elitización creciente de lo poético ni la enajenación que con respecto a ello muestra buena parte de una humanidad a su modo sensible a las manifestaciones poéticas.

Ahora, ¿qué sucede cuando los viejos fundamentos no fundan nada?, ¿cuál puede ser el sentido de la crítica de poesía, en este presente de insatisfacción crítica ante la crítica, en este momento de disolución del objeto crítico, de difuminación de presencias poéticas claras? Contra lo que cabría suponer, a instancias de cierta actitud hostil a la crítica de poesía en sí - como la de Steiner, en algunos momentos-, ésta no puede ni debe desaparecer del amplio ámbito de lo poético. En todo caso, su destino en esta era de ausencia de fundamentos - 0 , mejor dicho, cuando el único "fundamento" posible es una abigarrada dynamis de "nofundamentos" - consistirá en redimensionar y radicalizar su papel ontogenético de cara a lo poético.

En efecto, ya no es posible conformarse con una poiesis crítica que se agota en una valoración de entidades predefinidas como objetos de juicio. Salvo que sucumba a una tentación suicida, la crítica de poesía deberá tomar un giro paradójico: por un lado, ser más modesta y disminuir los alcances de su voluntad evaluadora; por el otro, ser más ambiciosa y compartir con la creación textual la responsabilidad de realizar lo poético, desde una plataforma referencial prácticamente vacía. De ese modo, mientras el para-qué de la crítica de poesía tradicional se ha subordinado -en el mejor de los casos-a las exigencias del juicio, el para-qué de una crítica de poesía topológica apuntaría a canalizar las virtualidades poéticas del texto desde sus propias potencialidades creativas. Así, el sentido judicativo de toda crítica de poesía sería trascendido por una poiesis crítica que actúe como parte del proceso de probar la realización poética del texto, en un contexto comunitario que implica un encuentro de fuerzas poéticas complementarias. La crítica de poesía deberá entender que no se trata sólo de interpretar, intuir y juzgar, sino de poner lo que le toca en la realización de lo poético. Asumir de otro modo la crítica de poesía significará que no se ha comprendido que su sentido no está en sí misma, sino en algo que la trasciende: lo poético.

10. Entender de esa manera el sentido de la crítica de poesía supone, por lo demás, superar la vieja dicotomía poeta/lector y reivindicar una comunidad de poetas-lectores y lectores-poetas. Asimismo, comporta encuadrar todo potencial crítico en el marco de un diálogo creador y realizador de lo poético. Si la crítica de poesía no opera como modalidad de un diálogo vivo y creador, terminará reduciéndose a un montón de excrecencias textuales, o convirtiéndose en monumento muerto a las desmesuras de la pasión crítica. Sólo será fecunda una crítica de poesía que se sustente en intuiciones y juicios que repercutan directamente en la producción poética de una comunidad dada, no en una creación discursiva paralela a dicha producción.

Una crítica de poesía ejercida de esa manera constituirá, de hecho, un factor de configuración, dinamización y revitalización de comunidades poéticas; es decir, de espacios relacionales de cumplimiento de lo poético. No es posible una crítica de poesía "pura", absoluta, ajena a determinaciones comunitarias. Si la actividad crítica comporta una 
intuición hermenéutica y judicativa, ésta remite necesariamente a patrones de interpretación y de valoración; esto es, referencias de sentido y valores. Estos tampoco son "puros"; dependen también de la dinámica de la propia crítica de poesía. De modo que se da una interdependencia entre ambos términos de la relación señalada. Los valores poéticos condicionan no sólo la creación textual, sino la lectura, la exégesis y la apreciación críticas, al tiempo que éstas determinan a aquéllos. Así, otra de las razones de ser de la crítica de poesía consistirá en esa necesidad de procesar y recrear referentes hermenéuticos y axiológicos, a la par de que recurra a ellos para contribuir a hacer posible lo poético.

Esta manera de entender y revalorar la crítica de poesía también debe actuar como soporte de un examen del movimiento crítico de nuestro tiempo (incluyendo el que se conoció durante los años 70). De hecho, no estará de más desandar los pasos dados por la crítica de poesía de las últimas tres décadas en América Latina y reconsiderar la producción poética conocida en ese lapso. Es conocida la complejidad de las ligaduras entre el conocimiento del presente y la comprensión del pasado. Aquí no se añadirá nada al respecto. Lo que sí cabe hacer es recordar que toda reconceptuación crítica del presente actúa como un "lente" con el que nos dispondremos a ver el pasado. En lo que concierne a la crítica de poesía, se puede recurrir a un caso ilustrativo de gran interés. Como es bien sabido, el grupo de excelentes poetas y críticos que preparó la antología Poesía en movimiento (publicada por primera vez en 1966 y decisivamente influyente en los años 70) decidió excluir de la misma una selección de las valiosas obras de Manuel Ponce, Eduardo Lizalde y Guillermo Fernández. Una consecuencia lógica de la manera cómo se ha venido entendiendo la crítica de poesía. Ese hecho no derivó, sin embargo, en la anulación poética ni histórica de dichas obras. A partir de determinados criterios se le puso un serio obstáculo al proceso de realización de las referidas obras, desde el momento de su eventual divulgación en una comunidad poética lo más amplia posible. Dicho de otro modo, la producción textual de Ponce, Lizalde y Fernández encontró cerrado uno de los más importantes caminos del diálogo vivo, creativo y realizador. A causa de ello podría decirse que la creación textual de dichos poetas "no existe" para importantes zonas de una macrocomunidad poética. Sin embargo, allí donde ha tenido lugar ese diálogo, allí donde la crítica de poesía ha actuado con una intención transvalorativa, se ha puesto a prueba dicha creación y se ha manifestado como una interesantísima obra de indiscutible valia.

Lo que estaría planteado, pues, sería un esfuerzo por elaborar una auténtica ontología nueva de lo poético, en virtud de la cual fuera posible un redimensionamiento de la crítica de poesía. Dos empresas teóricas de alto vuelo que habrán de repercutir, tanto en la manera de abordar un balance de la crítica de poesía de los últimos tiempos como en el modo de ejercerla en el porvenir. 